\title{
CORRECTION
}

\section{Correction: An integration of complementary strategies for gene-expression analysis to reveal novel therapeutic opportunities for breast cancer}

\author{
Andrea H Bild ${ }^{* 1,2}$, Joel S Parker,3,4, Adam M Gustafson ${ }^{5}$, Chaitanya R Acharya ${ }^{2}$, Katherine A Hoadley ${ }^{3,4}$, Carey Anders², \\ P Kelly Marcom², Lisa A Carey ${ }^{3,7}$, Anil Potti ${ }^{2}$, Joseph R Nevins ${ }^{2}$ and Charles M Perou ${ }^{3,4,6,8}$ \\ See related research by Bild et al., http://breast-cancer-research.com/content/11/4/R55
}

In our previous publication [1], Figure 4 involved the analysis of chemotherapy-response signatures (as carried out independently by author AP and described in a 2006 Nature Medicine article [2,3]). It has recently been determined that the chemotherapy-response signatures in [2] are not reproducible, causing retraction of that article [3]. As such, the results presented in Figure 4 of our original paper [1] are no longer valid.

We believe that the data presented in Figures 1-3 of our article remain valid. However, as Figure 4 can no longer be considered valid, portions of [1] are no longer applicable, including the Materials and Methods section entitled "Chemosensitivity signatures", the Results section entitled "Genomic signatures that predict response to cytotoxic chemotherapeutics", and other statements in the Abstract, Introduction, Results, Discussion, and Conclusions sections that refer directly or indirectly to the integration of chemotherapy-response signatures into the analytical approach presented in the manuscript. As such, the focus of the manuscript on the utility of an integrated approach using three complementary strategies for gene expression analysis (i.e. breast cancer intrinsic subtype analysis, pathway prediction and chemotherapyresponse signatures) should now be interpreted as referring exclusively to the integration of two complementary strategies.

\section{Competing interests}

The authors declare that they have no competing interests.

\section{Author details}

'Department of Pharmacology and Toxicology, University of Utah, 112 Skaggs Hall, Salt Lake City, UT 84112, USA. 'Duke Institute for Genome Sciences \& Policy, Duke University Medical Center, 2121 CIEMAS, Durham, NC 27701, USA. 'Lineberger Comprehensive Cancer Center, University of North Carolina, 102 Mason Farm Road, Chapel Hill, NC 27599, USA. ${ }^{4}$ Department of Genetics, University of North Carolina, 120 Mason Farm Road, Chapel Hill, NC 27599, USA. ${ }^{5}$ The Pulmonary Center, Boston University School of Medicine, 715 Albany St, Boston, MA 02118, USA. ${ }^{6}$ Department of Pathology \& Laboratory Medicine, University of North Carolina, Chapel Hill, NC 27599, USA. 'Division of Hematology/Oncology, Department of Medicine, University of North Carolina, Chapel Hill, NC 27599, USA. ${ }^{8}$ Carolina Center for Genome Sciences, 5016 Genetic Medicine Building, University of North Carolina, Chapel Hill, NC 27599, USA.

Published: 12 July 2011

\section{References}

1. Bild AH, Parker JS, Gustafson AM, Acharya CR, Hoadley KA, Anders C, Marcom PK, Carey LA, Potti A, Nevins JR, Perou CM: An integration of complementary strategies for gene-expression analysis to reveal novel therapeutic opportunities for breast cancer. Breast Cancer Res 2009, 11:R55.

2. Potti A, Dressman HK, Bild A, Riedel RF, Chan G, Sayer R, Cragun J, Cottrill H, Kelley MJ, Petersen R, Harpole D, Marks J, Berchuck A, Ginsburg GS, Febbo P, Lancaster J, Nevins JR: Genomic signatures to guide the use of chemotherapeutics. Nat Med 2006, 12:1294-1300.

3. Potti A, Dressman HK, Bild A, Riedel RF, Chan G, Sayer R, Cragun J, Cottrill H, Kelley MJ, Petersen R, Harpole D, Marks J, Berchuck A, Ginsburg GS, Febbo P, Lancaster J, Nevins JR: Retraction: Genomic signatures to guide the use of chemotherapeutics. Nat Med 2011, 17:135.

\section{doi:10.1186/bcr2909}

Cite this article as: Bild AH, et al:: Correction: An integration of complementary strategies for gene-expression analysis to reveal novel therapeutic opportunities for breast cancer. Breast Cancer Research 2011, 13:406.
*Correspondence: andreab@genetics.utah.edu

'Department of Pharmacology and Toxicology, University of Utah, 112 Skaggs Hall, Salt Lake City, UT 84112, USA

Full list of author information is available at the end of the article 